Saudi Journal of Oral and Dental Research

Abbreviated Key Title: Saudi J Oral Dent Res

ISSN 2518-1300 (Print) |ISSN 2518-1297 (Online)

Scholars Middle East Publishers, Dubai, United Arab Emirates

Journal homepage: https://saudijournals.com

\title{
Diagnostic Dilemma of Dentigerous Cyst Mimicking a Radicular Cyst: A Case Report
}

\author{
Dr. Sourav Bose ${ }^{1}$, Dr. Jaideep Sur ${ }^{2 *}$, Dr. Fatima $\mathrm{Khan}^{3}$, Dr. Deeplaxmi Dewangan ${ }^{4}$, Dr. Ayesha Roul ${ }^{5}$ \\ ${ }^{1}$ Post graduate in Oral Medicine \& Radiology, Rungta college of dental sciences \& Research, Bhilai, Chattisgarh, 490024, India \\ ${ }^{2}$ Professor and Head of the Department, (MDS in Oral Medicine and Radiology), Rungta College of Dental Sciences and Research, \\ Bhilai, Chattisgarh, 490024, India \\ ${ }^{3,4}$ Reader, (MDS in Oral Medicine and Radiology), Rungta College of Dental Sciences and Research, Bhilai, Chattisgarh, 490024, \\ India \\ ${ }^{5}$ Post Graduate in Oral Medicine, Rungta College of Dental Sciences and Research, Bhilai, Chattisgarh, 490024, India
}

DOI: $\underline{\text { 10.36348/sjodr.2021.v06i03.001 }}$ | Received: 22.02 .2021 | Accepted: 04.03.2021 | Published: 10.03 .2021

*Corresponding author: Dr. Jaideep Sur

\section{Abstract}

Dentigerous cysts are the developmental cyst of odontogenic origin caused by the accumulation of fluid between the reduced enamel epithelium and the crown of an unerupted tooth usually in the second and third decade of life. It surrounds the crown of the unerupted or impacted tooth. It has a prevalence of $22.6 \%$ overall and $4-9 \%$ among children up to 10 years whereas radicular cyst shows a prevalence of $54.7 \%$. In this article, a case of rare occurrence of dentigerous cyst in a 10-year-old child and its treatment are presented. The dentigerous cyst was fully enucleated and the deciduous second molar and permanent second premolar tooth was removed from the mandibular right premolar region.

Keywords: Dentigerous cysts, unerupted tooth, impacted tooth, unilocular.

Copyright (C) 2021 The Author(s): This is an open-access article distributed under the terms of the Creative Commons Attribution 4.0 International License (CC BY-NC 4.0) which permits unrestricted use, distribution, and reproduction in any medium for non-commercial use provided the original author and source are credited.

\section{INTRODUCTION}

Dentigerous cyst is an odontogenic cyst which is generally associated with an unerupted tooth. It forms around the crown of an unerupted tooth which begins when fluid starts to accumulate in the layers of reduced enamel epithelium and the crown of an unerupted tooth [1]. It accounts for the second most common type of odontogenic cyst with a prevalence of $22.6 \%$ [2]. Most commonly, it involves the mandibular and maxillary third molar, maxillary permanent canines, followed by mandibular premolars and rarely maxillary premolars $[3,4]$. These cysts usually show no signs and are usually identified by a radiographic analysis. In the radiographic analysis, the dentigerous cyst has a welldefined sclerotic boundary and a well-demarcated unilocular radiolucency around the crown of the unerupted teeth whereas radicular cysts appear as round or pear-shaped, unilocular, radiolucent lesions in the periapical region [5-7]. Because the cyst can increase in size, surgical removal of the lesion and teeth involved, or decompression to save the teeth involved, is suggested [8]. The prevalence in children is relatively low, with 4-9\% of these cysts occurring in the first 10 years after birth [9].

This case report highlights a rare case of dentigerous cyst associated with an unerupted mandibular right second premolar and its surgical management in a 10-year-male child patient.

\section{CASE REPORT}

A 10-year-old male child patient reported to the department of Oral medicine and Radiology, Rungta College of Dental Sciences \& Research, Chhattisgarh with a chief complaint of swelling on the right lower side of the face. The patient noticed a swelling 2 months back on the right side of the face, for which he underwent root canal therapy in a dental clinic. But swelling gradually increased to the present size with no history of pain associated with the swelling.

On general examination the patient was healthy and well-oriented with time \& surroundings, without any past medical history. Patient had undergone root canal treatment in 85 one month back for the same complaint of swelling. On extra oral examination, a 
solitary diffuse swelling was present on the right part of the mandible extending superio-inferiorly from $1 \mathrm{~cm}$ below the ala-tragus line to lower border of mandible and antero-posteriorly from the parasympyseal region to the ramus of the mandible measuring approximately $2 * 2 \mathrm{~cm}$. (Figure-1). Intraoral examination revealed a bony hard swelling in 8485 region, with obliteration of buccal vestibule (Figure $2 \mathrm{a}, 2 \mathrm{~b}$ ). The associated tooth 85 was nonvital and has been endodontically treated for caries previously. Co-relating the history and clinical examination a provisional diagnosis of periapical abscess was given with differential diagnosis of radicular cyst and dentigerous cyst.

Panoramic radiography (OPG) was performed for radiological analysis and revealed (Figure-3) the presence of a unilocular radiolucent cystic lesion measuring approximately $3 * 3 \mathrm{~cm}$ associated with the unerupted mandibular right second permanent premolar crown with clear internal structure and a sclerotic border aligned. Incomplete root formation was seen with 45 and a radiopacity was also appreciated near the lower border of the cystic lesion suggestive of a foreign material.

Based on the radiological examination, a provisional diagnosis of dentigerous cyst was made. The contents of the swelling were aspirated and sent for further investigations which revealed a clear strawcoloured fluid (Figure-4).

Under local anaesthesia, the deciduous molars $(84,85)$ was first removed with informed consent followed by a crevicular incision with an anterior release, stretching from the canine to the first molar. The total thickness of the mucoperiosteal flap was raised to reveal the lesion and surgical enucleation of the cystic area was done along with the extraction of the unerupted 45 (Figure 5a \& 5b). The area was closed primarily with suture.

The specimen sent for histopathological examination. Connective tissue stroma was thick \& fibrous and has been infiltrated with chronic inflammatory cells. Cystic lining has an epithelium of 4-6 layers cell thickness overlying the connective tissue stroma suggestive of inflammatory dentigerous cyst (Figure-6).

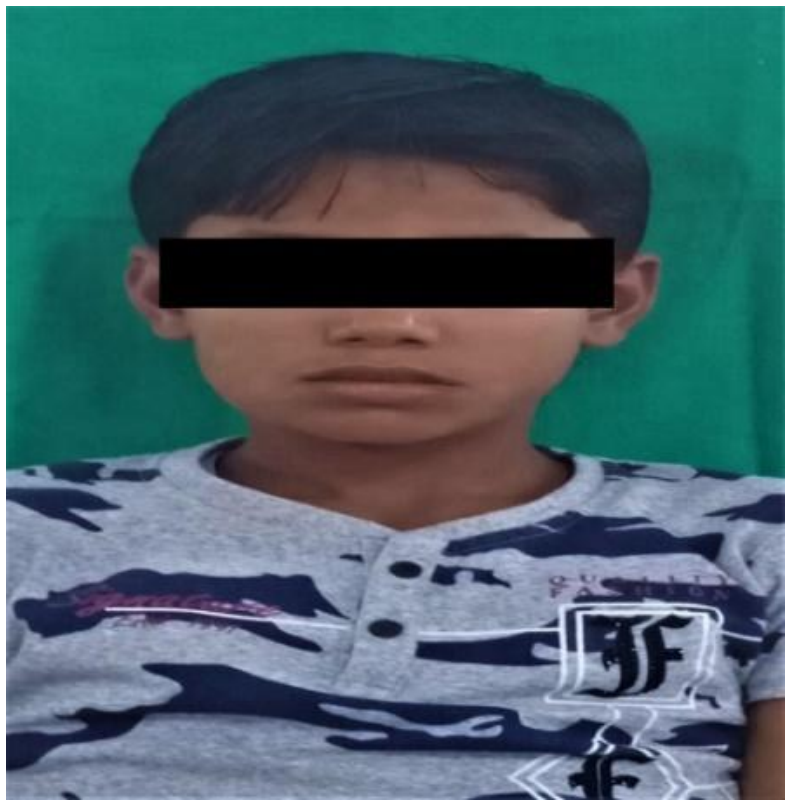

Fig-1: Extraoral Clinical Photograph

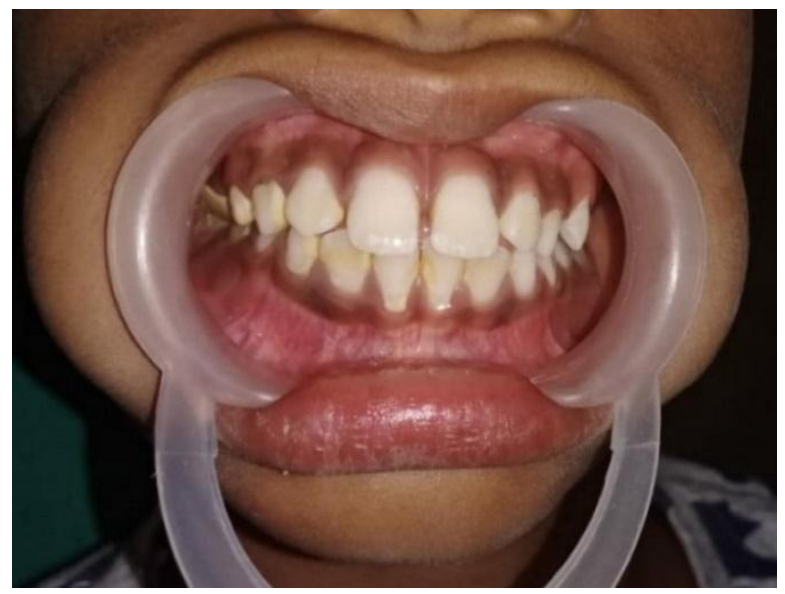

Fig-2a: Intraoral Clinical Photograph

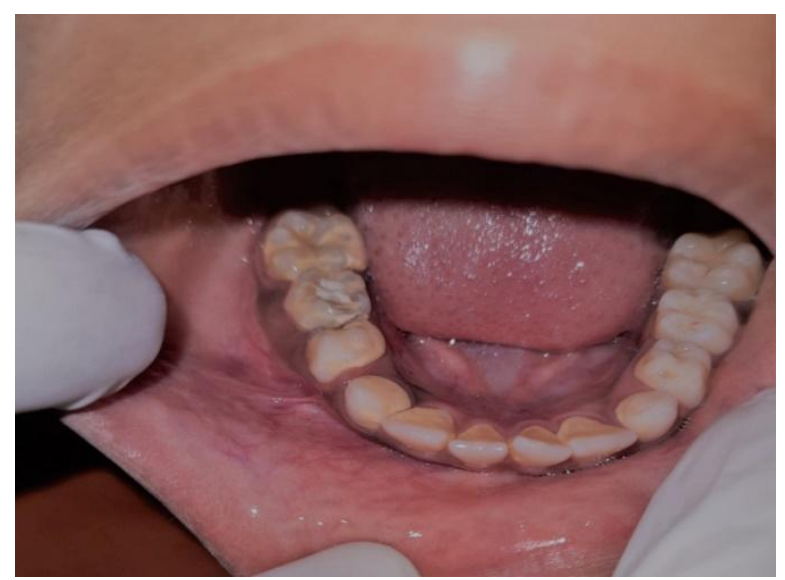

Fig-2b: Intraoral Clinical Photograph 


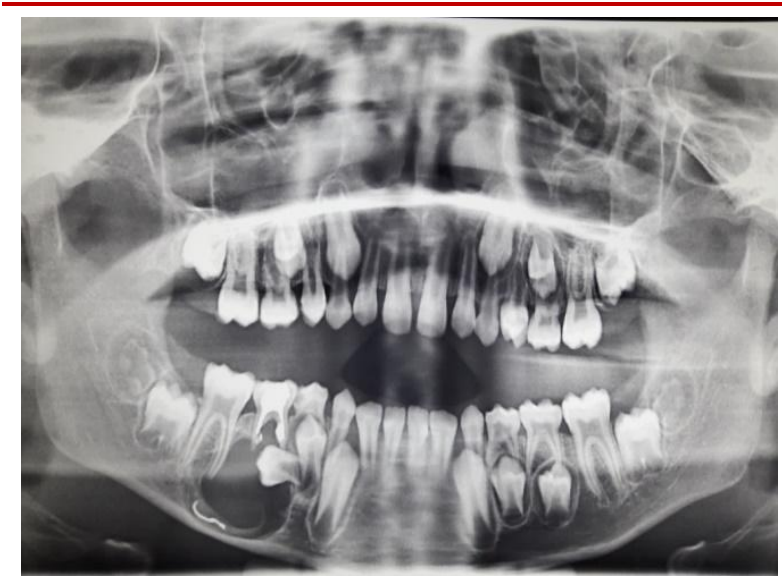

Fig-3: Pre-operative Orthopantamograph

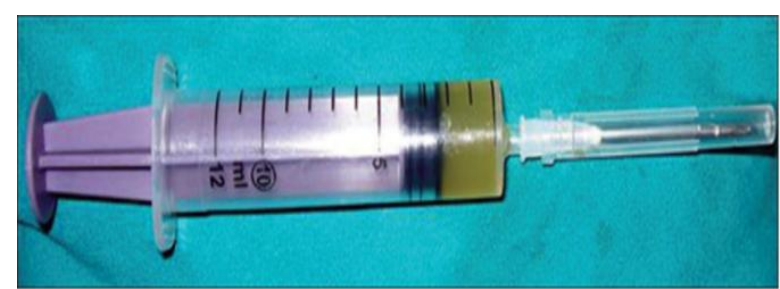

Fig-4: Fine Needle aspiration of the cystic fluid

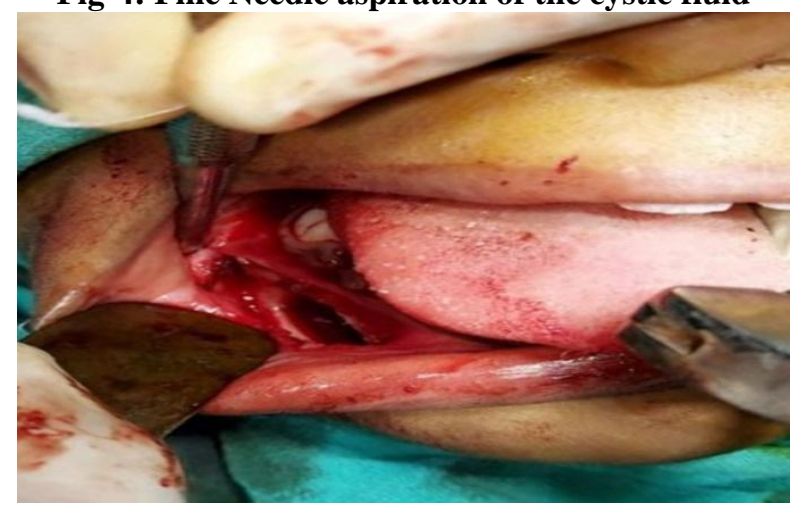

Fig-5a: Crevicular incision with anterior release

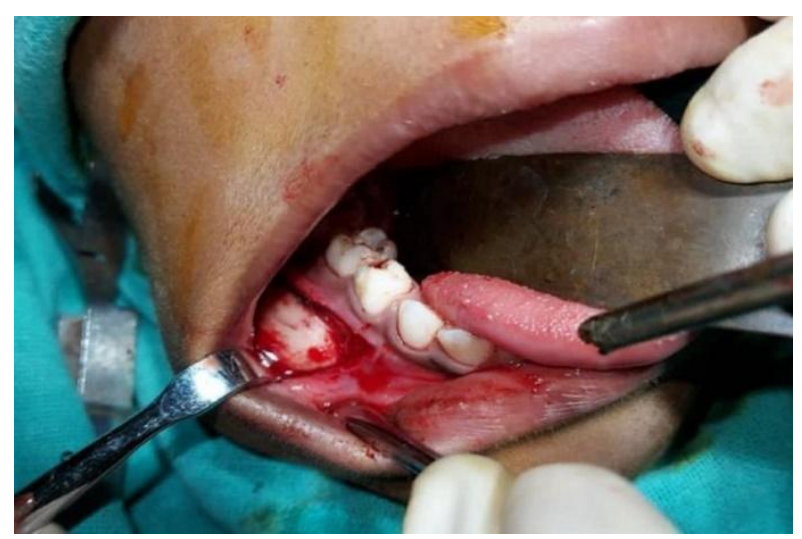

Fig-5b: Cystic Enucleation

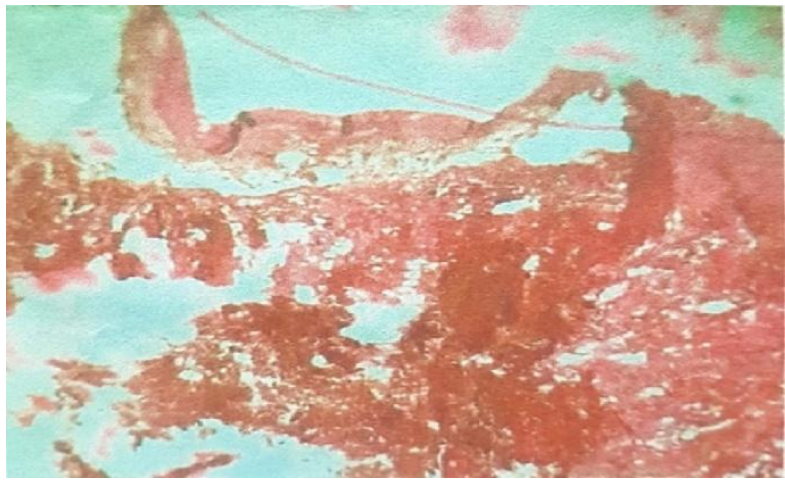

Fig-6: Photomicrograph (high power) showing cystic epithelial lining

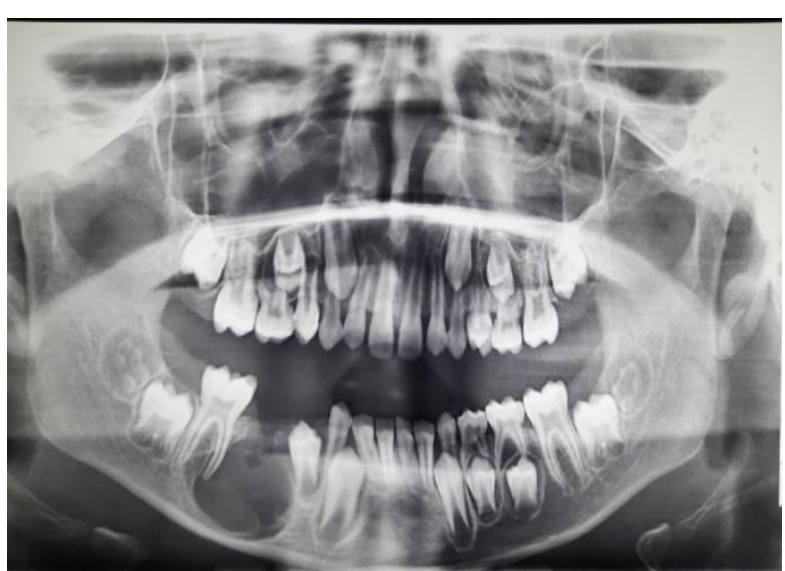

Fig-7: Post operative Orthopantamograph of 2month follow up shows bone formation

\section{DISCUSSION}

Dentigerous cyst is seen with the crown of unerupted or impacted teeth. It induces widening of the cortical plate and results in asymmetry of face [1]. It appears as well-defined unilocular radiolucency and asymptomatic lesion which is identified by radiographic analysis $[1,2]$. Generally dentigerous cyst occurs in the second and third decades of life but prevalence in children is quite low and rare $(4-9 \%)[1,9]$.

Dentigerous cyst is commonly associated with impacted $3^{\text {rd }}$ molars or impacted canines, whereas in our case impacted second permanent premolar was associated which was similar to that reported by Hedge et al., [7].

A series of three cases of dentigerous cyst mimicking a radicular cyst in young child was first reported by Wood et al., [3]. Similar cases were recently reported by Gupta et al., \& Shakuntala et al., where a dentigerous cyst mimicking a large radicular cyst in non-syndromic child less than 10 years of age $[4,5]$. 
Jaideep Sur et al; Saudi J Oral Dent Res, Mar, 2021; 6(3): 112-115

The treatment of choice may depend on considerations such as the size and position of the cystic lesion. Total cyst enucleation with primary closure or marsupialisation are effective ways to manage these lesions in children $[9,10]$. The cyst marsupialization was proposed as the treatment of choice in dentigerous cyst in children in an attempt to give the unerupted tooth a chance to erupt but the biggest drawback of the marsupialization is that pathologic tissue is left in the jaw without a detailed histological analysis [11]. Enucleation with primary closure was the treatment of choice in our case as the cyst was very small and of a central variety and was firmly attached to the unbroken premolar. A 2-month follow-up of the patient has been done which showed no signs of recurrence (Figure-7).

\section{CONCLUSION}

Since dentigerous cysts are typically asymptomatic and may gradually increase to a significant size with limited signs, early clinical and radiographic diagnosis is critical so that initial care and prompt treatment can be done. The present case depicts a rare case of dentigerous cyst associated with mandibular premolar mimicking a radicular cyst.

\section{Support: NIL}

\section{Conflicts of interest: NIL}

\section{REFERENCES}

1. Shear, M., \& Speight, P. (2007). Dentigerous cyst. In: Shear, M., editor; Cysts of the oral and maxillofacial regions. 4th ed. Oxford: WileyBlackwell pub.

2. Nadaf, A., Farooq, S., \& Khuroo, M. (2018). Restrospective clinic-pathological study of 106 odontogenic cyst among Kashmiri population. IJCMSR, 3(1), 53-56.
3. Wood RE, Nortjé CJ, Padayachee A, Grotepass F. Radicular cysts of primary teeth mimicking premolar dentigerous cysts: report of three cases. ASDC J Dent Child. 1988 Jul-Aug;55(4):288-90.

4. Gupta, P., Jawanda, M. K., Narula, R., \& Singh, J. (2016). Inflammatory dentigerous cyst mimicking a periapical cyst. Journal of the International Clinical Dental Research Organization, 8(1), 6366.

5. Shakuntala, B. S., Kulkarni, M. P., \& Yoshang, J. (2018). A rare case of radicular cyst mimicking an inflammatory dentigerous cyst in a 6-year-old child. Int J Sci Res, 7(12), 38-40.

6. Kalaskar, R. R., Tiku, A., \& Damle, S. G. (2007). Dentigerous cysts of anterior maxilla in a young child: A case report. Journal of Indian Society of Pedodontics and Preventive Dentistry, 25(4), 187 190.

7. Passi, S., Gauba, K., Agnihotri, A., \& Sharma, R. (2008). Dentigerous cyst in primary dentition: A case report. Journal of Indian Society of Pedodontics and Preventive Dentistry, 26(4), 168.

8. Hegde, R. J., Khare, S. S., \& Devrukhkar, V. N. (2013). Dentigerous Cyst in a young child: Clinical Insight and A Case report. Journal of Indian Society of Pedodontics and Preventive Dentistry, 31(3), 209-211.

9. Deboni, M. C. Z., Brozoski, M. A., Traina, A. A., Acay, R. R., \& Naclério-Homem, M. D. G. (2012). Surgical management of dentigerous cyst and keratocystic odontogenic tumor in children: a conservative approach and 7-year followup. Journal of applied oral science, 20(2), 282285.

10. Motamedi, M. H. K., \& Talesh, K. T. (2005). Management of extensive dentigerous cysts. British dental journal, 198(4), 203-206.

11. Demiriz, L., Misir, A. F., \& Gorur, D. I. (2015). Dentigerous cyst in a young child. European journal of dentistry, 9(4), 599-602. 